\title{
Atmospheric gravity waves in the Red Sea: a new hotspot
}

\author{
J. M. Magalhaes ${ }^{1}$, I. B. Araújo ${ }^{2}$, J. C. B. da Silva ${ }^{2,5}$, R. H. J. Grimshaw ${ }^{3}$, K. Davis ${ }^{4}$, and J. Pineda ${ }^{4}$ \\ ${ }^{1}$ Centro de Oceanografia and Departamento de Engenharia Geográfica, Geofísica e Energia (DEGGE), Faculdade de Ciências \\ da Universidade de Lisboa, Campo Grande, 1749-016 Lisboa, Portugal \\ ${ }^{2}$ CIMAR/CIIMAR - Centro Interdisciplinar de Investigação Marinha e Ambiental, Rua dos Bragas 289, 4050-123 Porto, \\ Portugal \\ ${ }^{3}$ Department of Mathematical Sciences, Loughborough University, Loughborough, LE11 3TU, UK \\ ${ }^{4}$ Biology Department, MS 50, Woods Hole Oceanographic Institution, Woods Hole, Massachusetts 02543, USA \\ ${ }^{5}$ Departamento de Geociências, Ambiente e Ordenamento do Território, Universidade do Porto, Rua do Campo Alegre, 687, \\ 4169-007, Porto, Portugal
}

Received: 12 June 2010 - Revised: 5 January 2011 - Accepted: 18 January 2011 - Published: 3 February 2011

\begin{abstract}
The region of the Middle East around the Red Sea (between $32^{\circ} \mathrm{E}$ and $44^{\circ} \mathrm{E}$ longitude and $12^{\circ} \mathrm{N}$ and $28^{\circ} \mathrm{N}$ latitude) is a currently undocumented hotspot for atmospheric gravity waves (AGWs). Satellite imagery shows evidence that this region is prone to relatively high occurrence of AGWs compared to other areas in the world, and reveals the spatial characteristics of these waves. The favorable conditions for wave propagation in this region are illustrated with three typical cases of AGWs propagating in the lower troposphere over the sea. Using weakly nonlinear long wave theory and the observed characteristic wavelengths we obtain phase speeds which are consistent with those observed and typical for AGWs, with the Korteweg-de Vries theory performing slightly better than Benjamin-Davis-Acrivos-Ono theory as far as phase speeds are concerned. ERS-SAR and Envisat-ASAR satellite data analysis between 1993 and 2008 reveals signatures consistent with horizontally propagating large-scale internal waves. These signatures cover the entire Red Sea and are more frequently observed between April and September, although they also occur during the rest of the year. The region's (seasonal) propagation conditions for AGWs, based upon average vertical atmospheric stratification profiles suggest that many of the signatures identified in the satellite images are atmospheric internal waves.
\end{abstract}

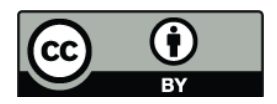

Correspondence to: J. C. B. da Silva (jdasilva@fc.up.pt)

\section{Introduction}

Internal waves (IWs) are ubiquitous in the ocean and atmosphere, and their ability to play an important role in densitystratified fluid dynamics, make them an important topic of research, which contributes to several scientific areas ranging from biological mixing and exchange processes, to ocean and atmospheric forecasting (Grimshaw, 2002; Vlasenko et al., 2005; da Silva et al., 2009). Atmospheric IWs in particular constitute a potentially serious hazard to aircrafts operating at low altitudes (Christie and Muirhead, 1983; Bedard et al., 1986). There have been reports of air crashes on approach and take-off related to encounters with largeamplitude AGWs in Australia (Christie and Muirhead, 1983) that essentially occur due to unexpected clear air turbulence and low level wind shear. These are capable of causing insufficient lift at take-off or disturbances to the glide path that may lead to undershoot or overshoot of the runway.

Remote sensing image data has been increasing IW observations worldwide. In particular, satellite imagery have proved very useful, adding a significant number of observations to the meteorology and oceanography literature (Jackson and Apel, 2002; Jackson, 2004, 2007; da Silva et al., 2007, 2009; da Silva and Magalhaes, 2009).

Roughness patterns on the ocean surface can be produced both by oceanic and atmospheric IWs, and are easily detected in Synthetic Aperture Radar (SAR) images. In these images, oceanic IW patterns arise either as a result of hydrodynamic modulation of Bragg waves or wave damping due to surface films (Alpers, 1985; da Silva et al., 2000), while atmospheric imaging of IWs is a consequence of wind stress variability associated with wave propagation (Alpers and Stilke, 1996).

Published by Copernicus Publications on behalf of the European Geosciences Union and the American Geophysical Union. 


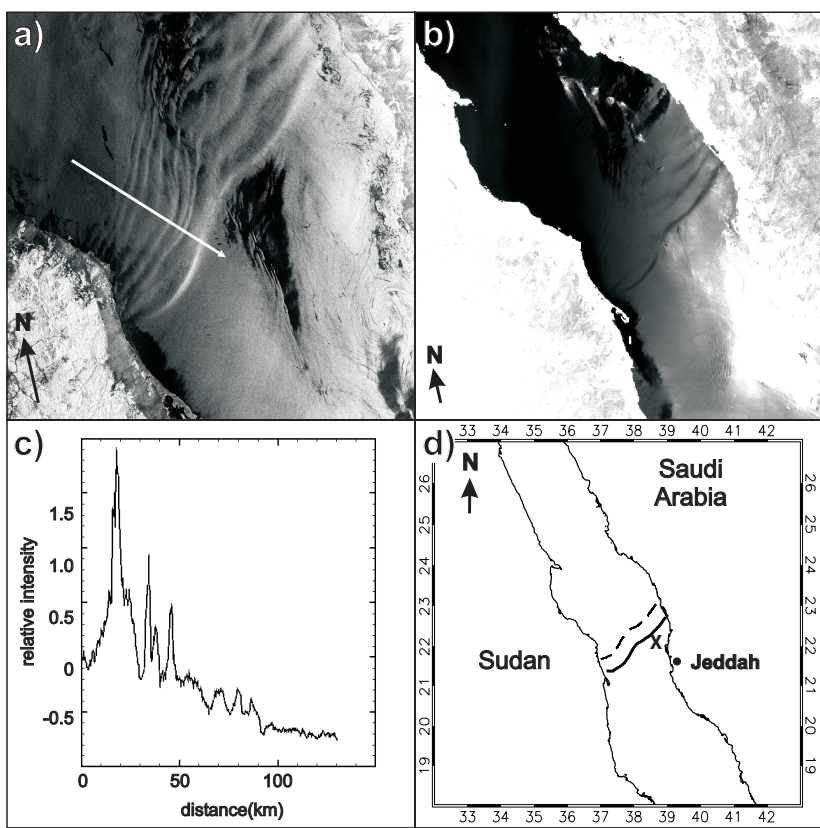

Fig. 1. Case study of an AGW occurrence in the Red Sea near Jeddah: (a) subset of an Envisat-ASAR image acquired at 07:26 (UTC) dated 11 May 2004. A transect profile is marked with a white arrow across the AGW packet (extending from NW to SE); (b) subset of a near-infrared MODIS-Terra image acquired at 08:12 (UTC) dated 11 May 2004; (c) relative intensity taken from the profile in the Envisat-ASAR image in (a); (d) compiled feature map with the geographic locations of the leading waves in (a) (dashed line) and (b) (solid line), $\mathrm{X}$ marks the location where in situ measurements were made $\left(22^{\circ} 04.509^{\prime} \mathrm{N}, 38^{\circ} 46.181^{\prime} \mathrm{E}\right)$ near Abu Madafi.

Furthermore, atmospheric IW condensation patterns in their ascending branches, and solar specular reflection (sunglint), may also be detected in near-infrared images (da Silva and Magalhaes, 2009).

Despite these different imaging mechanisms, in some cases discrimination between oceanic and atmospheric signatures in satellite imagery is difficult or even impossible and ambiguities often arise such as those exemplified by the discussions following the work of Kim et al. (2005a) (Zheng, 2005; Kim et al., 2005b; Gan et al., 2008). The global IW survey undertaken by Jackson (2007) (using MODIS imagery), showed that oceanic IWs are present in the Red Sea region (Fig. 1 in Jackson, 2007). Since we will clearly show here that AGWs are also present in the Red Sea, we alert for the possibility of misinterpretation in future studies. We stress that the problem of misclassification of IW satellite signatures is particularly severe in the Red Sea region because of the dry conditions and absence of roll clouds, and should therefore be taken under consideration especially when wavelengths approach values around 5-10 km.

AGW theories assume the existence of a waveguide, typically located in the lower layers of the troposphere, as a necessary condition for waves to propagate horizontally.
These waveguides often take the earth's surface as their lower boundary, and rely on some suitable trapping mechanism in the upper layers to confine the wave energy (Rottman and Grimshaw, 2002). Several trapping mechanisms capable of preventing wave energy to radiate away in the vertical have been identified and presented in the literature (Scorer, 1949; Crook, 1986, 1988; Rottman and Grimshaw, 2002; da Silva and Magalhaes, 2009). These depend on the Scorer parameter (Scorer, 1949) which is related with the atmospheric stability and the wind speed vertical profile.

This paper presents satellite based evidence that the region of the Middle East around the Red Sea is a newly found hotspot for AGWs. It also aims to contribute to the issue of distinguishing between oceanic and atmospheric IW signatures in satellite images. Section 2 begins with a detailed case study of an AGW propagating over the Red Sea together with a comparison with weakly nonlinear long wave theory (using both the Korteweg-de Vries and Benjamin-Davis-AcrivosOno models). This analysis is extended to a brief description of two further case studies at the end of Sect. 2. In Sect. 3 the seasonal frequency of IW observations in the Red Sea is characterized and correlated with the region's seasonal average vertical stratification.

\section{AGW case studies in the Red Sea}

A case of an AGW propagating over the central section of the Red Sea on 11 May 2004 (near Jeddah, Saudi Arabia) is presented in Fig. 1. This wave packet was captured in an Envisat-ASAR image acquired at 07:26 UTC, and in a MODIS-Terra image acquired at 08:12 UTC (Fig. 1a and b, respectively). These are typical examples of AGW signatures that are seen in SAR and near-infrared (841-876 nm) imagery of the Red Sea. In this case, surface signatures of the wave packet extend across the Red Sea indicating that the along-crest length of the leading wave is at least $248 \mathrm{~km}$ (the wave crests may extend even further inland, but are not visible in this case).

In Fig. 1a the wave crests appear as alternating bright and dark bands (due to backscatter variations) as a result of fluctuating surface wind speed between the downdraft and updraft portions of the oscillations (Alpers and Stilke, 1996; Li et al., 2004). The propagation direction of the wave packet is approximately $130^{\circ}$ (clockwise from North). The number of waves in the packet depends on the cross section chosen for the backscatter profile. At least 7 wave crests can be identified in the cross section in Fig. 1c, increasing to 9 waves in other sections. The distance between the leading and second wave of the packet is approximately $15 \mathrm{~km}$. The characteristic length scale for an individual solitary wave is between 2-8 km (Fig. 1c) and there is clearly an amplitude-ordered backscatter profile, which suggests rank-ordered amplitude waves. This is a prominent feature of dispersive "solitarylike" wave trains (Christie, 1989). Fewer wave crests can 

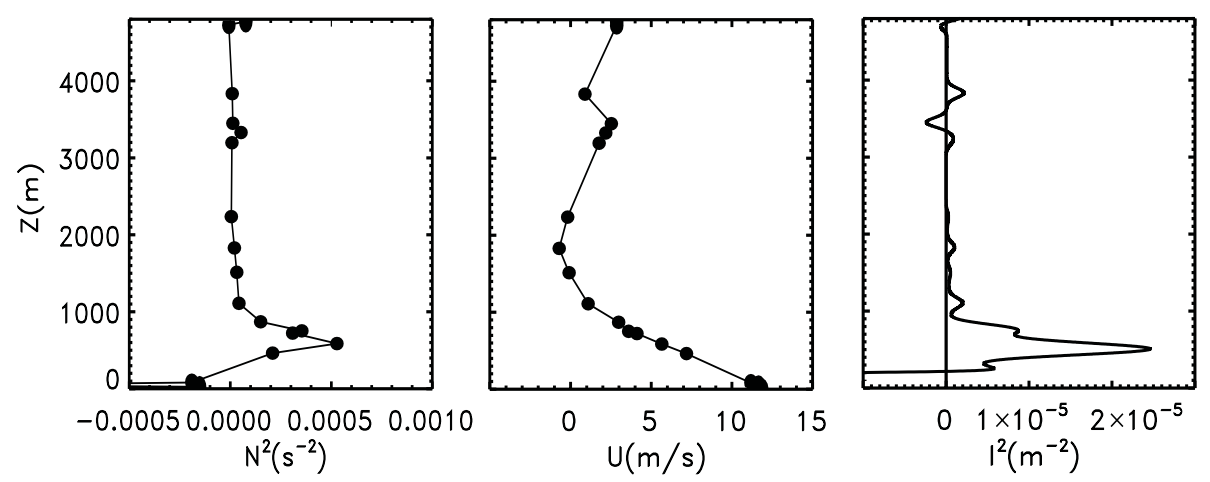

Fig. 2. Atmosphere's vertical structure and propagation conditions calculated using data from Jeddah weather station (11 May 2004 at 09:00 UTC). The buoyancy frequency is shown in (a); horizontal wind velocity in the direction of wave propagation in (b); and Scorer parameter in (c). The solid circles in (a) and (b) represent real data whilst the solid curves represent smoothed fits to the data. The $l^{2}$ solid curve is calculated values using $N^{2}$ and $U$ smoothed fits.

be identified in the near-infrared MODIS image (Fig. 1b) obtained $45 \mathrm{~min}$ later, where the surface expression of the waves appears as dark bands with no apparent cloud formations. The positions of the leading wave captured in both images are shown in Fig. 1d, from which an average propagation speed of $15.5 \mathrm{~m} \mathrm{~s}^{-1}$ was estimated (the phase speed actually varies along the wave front, from $17 \mathrm{~m} \mathrm{~s}^{-1}$ in the $\mathrm{NE}$ end, to $14 \mathrm{~m} \mathrm{~s}^{-1}$ in the opposite end). Assuming there is a background flow speed of $4.4 \mathrm{~m} \mathrm{~s}^{-1}$ along the propagation direction (suggested by the average $U$ within the waveguide, see Fig. 2b) the estimated intrinsic average phase speed is $11.1 \mathrm{~m} \mathrm{~s}^{-1}$. The characteristics of these waves make them comparable to the Australian Morning Glories (Smith, 1988; Christie, 1989; Rottman and Grimshaw, 2002), and to the AGWs in the Korean Peninsula (Gan et al., 2008) and in the Mozambique Channel (da Silva and Magalhaes, 2009).

AGWs, like their oceanic counterparts, are often modeled using weakly nonlinear long wave theories, even though the waves may be strongly nonlinear, see Smith (1988) and Rottman and Grimshaw (2002) for instance. The starting point is the Taylor-Goldstein equation based on linearized theory, given here in the Boussinesq approximation,

$d^{2} w / d z^{2}+\left(l^{2}-k^{2}\right) w=0$,

where

$l^{2}=N^{2} /(U-c)^{2}-U^{\prime \prime} /(U-c)$

is the Scorer parameter, $w$ is an eigenfunction for the vertical component of the velocity field (the actual vertical velocity is given by $\operatorname{Re}\{w(z) \exp (i k(x-c t))\}), z$ is the vertical coordinate, $N$ is the buoyancy frequency, $U$ is the horizontal wind speed (in the wave propagation direction), $c$ is the wave phase velocity, and $k$ is the horizontal wavenumber, while $U^{\prime \prime}$ is the second derivative of $U(z)$. A vertical profile of the Scorer parameter was calculated using the phase speed estimated from the pair of satellite images in Fig. 1a and $b$, in which the wave packet was observed close to the
Jeddah weather station $\left(22^{\circ} 41^{\prime} \mathrm{N}, 37^{\circ} 36^{\prime} \mathrm{E}\right)$. This was then used to investigate pre-conditions supporting wave propagation. Since $l^{2}-k^{2}$ in Eq. (1) can be interpreted as a vertical wavenumber then a layer where $l^{2}>k^{2}$ will be capable of sustaining vertical wave propagation, while evanescent solutions and trapping occur when $l^{2}<k^{2}$.

The vertical structure of the atmosphere for this case study is summarized in Fig. 2, and was calculated using data from the Jeddah weather station (at 09:00 UTC, 11 May 2004, which was acquired less than a hour after the MODIS satellite image in Fig. 1b). Figure 2a shows the vertical profile of the atmospheric stability, $N^{2}(z)$, Fig. $2 \mathrm{~b}$ shows a profile of the horizontal wind velocity $U$ in the direction of wave propagation, and Fig. 2c the Scorer parameter $l^{2}$. These results clearly show a layer (close to the ground) between approximately $200 \mathrm{~m}$ and $1000-1300 \mathrm{~m}$, where $N^{2}$ develops a sharp increase, peaking around $500 \mathrm{~m}$, and $l^{2}>0$, whereas above $1300 \mathrm{~m} l^{2} \approx 0$. Thus the vertical profile of the Scorer parameter in Fig. 2c is typical for a waveguide capable of sustaining horizontal wave propagation. This is a common mechanism to trap wave energy. Moreover, AGWs frequently occur when strong stratification occurs close to the earth's surface (Rottman and Grimshaw, 2002; da Silva and Magalhaes, 2009). Note that, in Eq. (2) $N^{2}$ tends to dominate over the other terms whenever sharp peaks in stability occur within the lower layers of the troposphere (in this case study $U$ also varies linearly when $l^{2}>0$, implying that $U^{\prime \prime} \approx 0$ and thus the second term is negligible compared to the first, see Fig. 2b). Note that here $l^{2} \gg k^{2}$ in the boundary layer, enabling the use of weakly nonlinear long wave theory as follows.

As is well-known, there are two weakly nonlinear long wave models commonly used for AGWs, namely the Korteweg-de Vries (KdV) equation or the Benjamin-DavisAcrivos-Ono (BDAO) equation. For the KdV case, the first step is to solve the Taylor-Goldstein Eq. (1) in the long wavelength limit $\left(k^{2}=0\right)$ in a waveguide $h<z<H$ with 
Table 1. List of values obtained by weakly nonlinear long wave analysis for the case study presented in Sect. 2, according to expressions $(3,4,5$ and 6$)$. $C_{\text {linear }}$ refers to the linear long wave phase speed solving Eq. (1) with the boundary condition indicated in the first line of the table. $\Phi$ refers to the modal function and the subscript indicates differentiation with respect to the vertical coordinate. See text for details.

\begin{tabular}{lcc}
\hline & $\mathrm{KdV}$ & $\mathrm{BDO}$ \\
\hline Upper boundary & $\phi=0$ at $H=3000 \mathrm{~m}$ & $\phi_{z}=0$ at $d=1300 \mathrm{~m}$ \\
$C_{\text {linear }}\left(\mathrm{m} \mathrm{s}^{-1}\right)$ & 14.4 & 15.4 \\
$I$ & 0.0476 & 0.0372 \\
$\delta$ & $3.9023 \times 10^{6}$ & $6.2365 \times 10^{3}$ \\
$\mu$ & 0.0164 & 0.0280 \\
$V\left(\mathrm{~m} \mathrm{~s}^{-1}\right)$ & 15.0 & 16.9 \\
Amplitude $(\mathrm{m})$ & 114 & 178 \\
\hline
\end{tabular}

the boundary conditions $w=0$ at $z=h, H$. Here we set $h=200 \mathrm{~m}$, but while it is clear that the waveguide is based on the strong stratification in the lower $1000 \mathrm{~m}$, it is not so clear how to choose $H$. This is a common issue in modeling AGWs (see Noonan and Smith, 1985; Smith, 1988; Rottman and Einaudi; 1992; Rottman and Grimshaw; 2002, for a discussion of the issues involved). Here we choose $H=3000 \mathrm{~m}$ based on the observation that the Scorer parameter is close to zero from approximately $2300 \mathrm{~m}$ up to this level (see Fig. 2c) implying that waves are trapped below. This is a quite small value for $H$, and a larger value could well be more appropriate (e.g. another choice is $H=3500 \mathrm{~m}$ where $l^{2}$ becomes negative). Nevertheless, we shall proceed with $H=3000 \mathrm{~m}$ and find that then the linear long wave phase speed for a first mode wave is $14.4 \mathrm{~m} \mathrm{~s}^{-1}$, which is slightly smaller than the observed propagation speed (approximately $15.5 \mathrm{~m} \mathrm{~s}^{-1}$ ). This phase speed and the associated modal functions $w(z)=(c-U) \phi(z)$ can now be used to construct a weakly nonlinear model for these waves, based on the KdV equation. This leads to an expression for the vertical displacement of a solitary wave (see Grimshaw, 2002, for instance),

$a \operatorname{sech}^{2} \kappa(x-V t) \phi(z), \quad$ where $\quad V-c=\frac{\mu a}{3}=4 \delta \kappa^{2}$.

The coefficients $\mu$ and $\delta$ are determined from the integral expressions

$$
\begin{aligned}
I \mu & =3 \int_{h}^{H}(c-U)^{2} \phi_{z}^{3} d z, \quad I \delta=\int_{h}^{H}(c-U)^{2} \phi^{2} d z, \\
I & =2 \int_{h}^{H}(c-U) \phi_{z}^{2} d z .
\end{aligned}
$$

Here $\phi(z)$ is normalized so that $\phi\left(z=z_{\mathrm{m}}\right)=1$ where $z_{\mathrm{m}}$ is the height where $\phi(z)$ achieves its maximum value. In or- der to use these expressions, in the present case, we need to estimate the observed wavelength (defined as $1 / \kappa$ from Eq. 3), corresponding to the width at an amplitude of $0.42 a$ (measured from a reference level unperturbed by the solitary wave). From Fig. $1 \mathrm{c}$, we estimate that $1 / \kappa$ is approximately $5000 \mathrm{~m}$, and using expressions (3), (4) for a mode 1 wave yields an amplitude $a=114 \mathrm{~m}$ and a nonlinear speed $V=15.0 \mathrm{~m} \mathrm{~s}^{-1}$ (see Table 1). Although this estimate of the phase speed is well within the observed range of values, the amplitude is somewhat smaller than we expected. However, we note that the expressions (3) are quite sensitive to the estimated value of $1 / \kappa$. For instance, reducing the wavelength by a half increases the amplitude by a factor of four. Increasing the waveguide height $H$ also leads to some improvement in these estimates, but brings the $\mathrm{KdV}$ model into a close similarity with the BDAO model discussed below. However, decreasing the waveguide height $H$ leads to a curious anomaly, in that the predicted wave is one of depression, because the coefficient $\mu$ becomes negative. Examining the structure of the modal functions, and the formula (4) for $\mu$, suggests that this unexpected effect is due to the wind shear in the bottom boundary layer. Since we expect AGWs riding on a bottom boundary layer to be waves of elevation, this reinforces the need to ensure that $H$ is taken sufficiently large.

As a result of this anomalous behavior of the $\mathrm{KdV}$ model, we turned instead to the BDAO model. Here it is assumed that the atmosphere is essentially unbounded above the lowlevel waveguide (that is $H \rightarrow \infty$ ). Then the Taylor-Goldstein Eq. (1) is solved instead in the waveguide $h<z<d$, with the boundary conditions that $\phi=0$ at $z=h$ as before, but with $\phi_{z}=0$ at $z=d$. We set $h=200 \mathrm{~m}$ as before, and set $d=1300 \mathrm{~m}$, since this is the level where $l^{2}$ first becomes very close to zero. This yields a linear long wave speed of $15.4 \mathrm{~m} \mathrm{~s}^{-1}$ which, while consistent with the linear long wave speed obtained from the $\mathrm{KdV}$ model $\left(14.4 \mathrm{~m} \mathrm{~s}^{-1}\right)$, is also slightly closer to that observed $\left(15.5 \mathrm{~m} \mathrm{~s}^{-1}\right)$ (see Table 1$)$. In place of Eq. (3) the vertical displacement of a solitary wave is now given by

$$
\frac{a \phi(z)}{1+\kappa^{2}(x-V t)^{2}}, \quad \text { where } \quad V-c=\frac{\mu a}{4}=\delta \kappa .
$$

$$
\begin{aligned}
I \mu & =3 \int_{h}^{d}(c-U)^{2} \phi_{z}^{3} d z, \quad I \delta=c^{2} \phi(z=d)^{2}, \\
I & =2 \int_{h}^{d}(c-U) \phi_{z}^{2} d z .
\end{aligned}
$$

Here the modal function $\phi(z)$ is normalized so that $\phi(d)=1$. Evaluating these expressions for a mode 1 wave, with a wavenumber $1 / \kappa=5000 \mathrm{~m}$ yields a nonlinear speed $V=$ $16.9 \mathrm{~m} \mathrm{~s}^{-1}$ (which overestimates the averaged value of 15.5 $\mathrm{m} \mathrm{s}^{-1}$ ) (see Table 1). The BDAO model predicts an amplitude $a=178 \mathrm{~m}$, which is larger than that from the KdV 
Table 2. Weakly nonlinear long wave analysis for the two case studies presented in the end of Sect. 2 (1 July 2007 and 17 May 2008 ). All times are in UTC. The upper boundaries are listed using " $H$ " for KdV and " $h$ " for BDO, and they represent the levels where $\Phi=0$ and $\Phi_{z}=0$, respectively. See text for more details.

\begin{tabular}{lcc}
\hline & $1 \mathrm{Jul} 2007$ & 17 May 2008 \\
\hline Satellite synergy & Terra 08:45 Aqua 10:20 & Envisat 07:22 Aqua 11:00 \\
Sounding & Jeddah 00:00 $\mathrm{h}$ & Jeddah 12:00h \\
$C_{\text {observed }}\left(\mathrm{m} \mathrm{s}^{-1}\right)$ & $3.7-4.8$ & $9.0-11.0$ \\
$\lambda_{\text {observed }}(\mathrm{m})$ & $\approx 4000$ & $\approx 3000$ \\
Upper boundary & $H=1200 \mathrm{~m} \& h=800 \mathrm{~m}$ & $H=2100 \mathrm{~m} \& h=400 \mathrm{~m}$ \\
Lower boundary & $100 \mathrm{~m}$ & Surface \\
$V\left(\mathrm{~m} \mathrm{~s}^{-1}\right)$ & $\mathrm{KdV}=4.8 \& \mathrm{BDO}=8.7$ & $\mathrm{KdV}=9.7 \& \mathrm{BDO}=11.5$ \\
Amplitude $(\mathrm{m})$ & $\mathrm{KdV}=30 \& \mathrm{BDO}=49$ & $\mathrm{KdV}=315 \& \mathrm{BDO}=420$ \\
\hline
\end{tabular}

model with $H=3000 \mathrm{~m}$. Note that the BDAO solitary wave amplitude is less sensitive to the wavelength than $\mathrm{KdV}$, as a decrease in the wavelength by a factor of two only doubles the amplitude.

Next, we extended the weakly nonlinear analysis to an additional two case studies, namely those of 1 July 2007, and 17 May 2008 (see Fig. 3). The results are summarized in Table 2 and suggest (similarly to the previous results) that the $\mathrm{KdV}$ phase speeds are well within the observed values, whereas the BDAO theory tends to overestimate the observed wave speeds. The amplitudes of both models (KdV and BDAO) are of the order of tens to hundreds of meters. However, they are generally smaller (although BDAO presents larger values than $\mathrm{KdV}$ ) in comparison with other results obtained independently for other AGWs such as the ones discussed in Porter and Smyth (2002).

Finally, while these theoretical estimates of AGW phase speeds are within the general regime of the observations, we note that it is possible the observed waves are strongly nonlinear, as is often the case for AGWs (see the review by Rottman and Grimshaw, 2002).

\section{SAR observations and seasonal average stratification}

All available SAR images from ERS-SAR and EnvisatASAR missions, between January 1993 and September 2008 (between $13^{\circ} 16^{\prime} \mathrm{N}$ and $29^{\circ} 46^{\prime} \mathrm{N}$ latitude and between $31^{\circ} 29^{\prime} \mathrm{E}$ and $44^{\circ} 30^{\prime} \mathrm{E}$ longitude), have been analyzed for the presence of wave-like signatures consistent with AGWs. These wave-like signatures were interpreted as AGWs based on spatial scales and patterns, for instance when their wavelengths were greater than $5 \mathrm{~km}$, and/or when there were no signs of refraction patterns close to the coast of the Red Sea. The latter criterion is certainly a valid one when ambiguity between atmospheric and oceanic internal waves is an issue. We note in passing that, in the near shore region of the Red Sea, wavelengths exceeding $5 \mathrm{~km}$ would not be realistic for oceanic internal waves, since in shallow seas internal wave speeds (and thus their wavelengths) are typically small (less than $2 \mathrm{~km}$ ). Internal wave-like signatures (believed to be of atmospheric nature) were distributed throughout most of the Red Sea, and were found in 92 radar images (23 ERS SAR and 69 ENVISAT ASAR). Such radar signatures can be observed throughout the year, with a clear increase in occurrence between April and September (Fig. 4a). A slight decrease is noticeable in August and no waves were found in November (monsoon period in this area). The dominant wave propagation directions (Fig. 5) vary approximately between $45^{\circ} \mathrm{N}$ and $110^{\circ} \mathrm{N}$ (NE and ESE), and between $245^{\circ} \mathrm{N}$ and $315^{\circ} \mathrm{N}$ (WSW and NW).

To support the atmospheric nature of most of the wave-like signatures and in order to study suitable trapping conditions in the atmosphere (and relate those results with the ones in Fig. 4a), pairs of satellite images (e.g. MODIS and SAR) are necessary to estimate phase speeds, and calculate the Scorer parameter (note that both phase speeds and $U$ are required to calculate $l^{2}$, see Eq. 2). However, there are not enough radar images to cast image pairs and estimate phase speeds, needed to obtain a daily record of $l^{2}$ (note also that MODIS Terra/Aqua synergy is difficult to detect internal waves in the same day, because sunglint is usually not present in the same area in both images, and thus one of the images usually does not display clear signatures of AGWs). Therefore, at the present time, it is not possible to make a statistical analysis of $l^{2}$, and this investigation is restricted to the analysis of the atmospheric stability $\left(N^{2}\right)$ as an important factor favoring the propagation of AGWs. We recall that $N^{2}$ plays a dominant role in determining waveguides capable of sustaining horizontal wave propagation near the sea surface (Eq. 2, and Sect. 2).

Upper air soundings were retrieved from the University of Wyoming website (http://weather.uwyo.edu/upperair/ sounding.html) to obtain atmospheric vertical profiles and study the seasonal variability of stratification (monthly averages). A detailed analysis of the atmospheric stability was undertaken where a daily vertical profile of $N^{2}$ was 
(a) MODIS Aqua 20070701

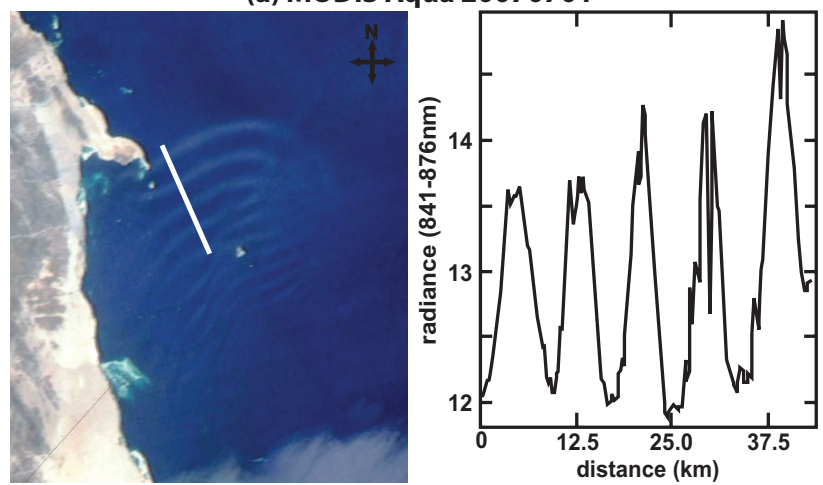

(b) Envisat ASAR 20080517
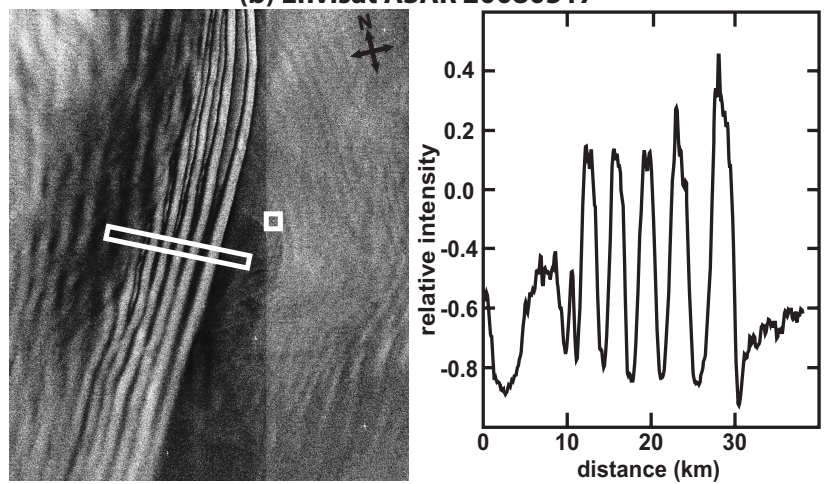

Fig. 3. Close-ups (subsets) for two case studies together with transect profiles represented by the white lines: (a) MODIS-Aqua image dated 1 July 2007 acquired at 10:20 UTC; (b) Envisat-ASAR image dated 17 May 2008 acquired at 07:22 UTC.

calculated for Jeddah station $\left(21.7^{\circ} \mathrm{N}, 39.2^{\circ} \mathrm{E}\right.$, located $17 \mathrm{~m}$ above Mean Sea Level), between 1993 and 2008. The maximum values of $N^{2}\left(N_{\max }^{2}\right)$, as well as the heights for which $N^{2}$ was at its maximum $\left(z_{\max }\right)$, were estimated from each of those profiles. The monthly average distributions of $N_{\max }^{2}$ and $z_{\max }$ (for the period 1993 to 2008) are presented in Fig. $4 \mathrm{~b}$ (standard deviations are shown in the form of error bars), which shows an increase in the stability maximum between April and September coincident with a decrease of $z_{\max }$ (when compared with the rest of the year). These variations are in close agreement with the period where IWs are more frequently observed in the SAR (see Fig. 4a).

This variability in the seasonal stratification affects the AGW propagation conditions as described by the curve of averaged $l^{2}$ as a function of month in year, shown in Fig. 4c. This curve represents the values of the Scorer parameter calculated from the monthly average distribution of $N_{\max }^{2}$ and $z_{\max }$, where each value is calculated using Eq. (2) at a level $z=z_{\max }$ and with stratification given by $N_{\max }^{2}$ (note the variability shown by error bars which represent the errors introduced by the standard deviations of $N_{\max }$ and $\left.z_{\max }\right)$. Here, $U$ has been taken from the first case study (11 May 2004) as an average over the waveguide (in that case considered to (a)

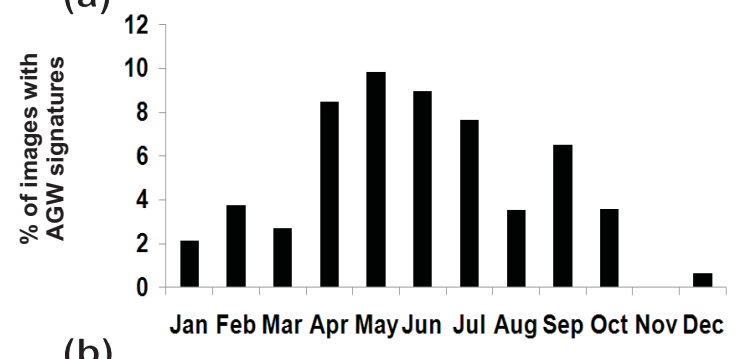

(b)
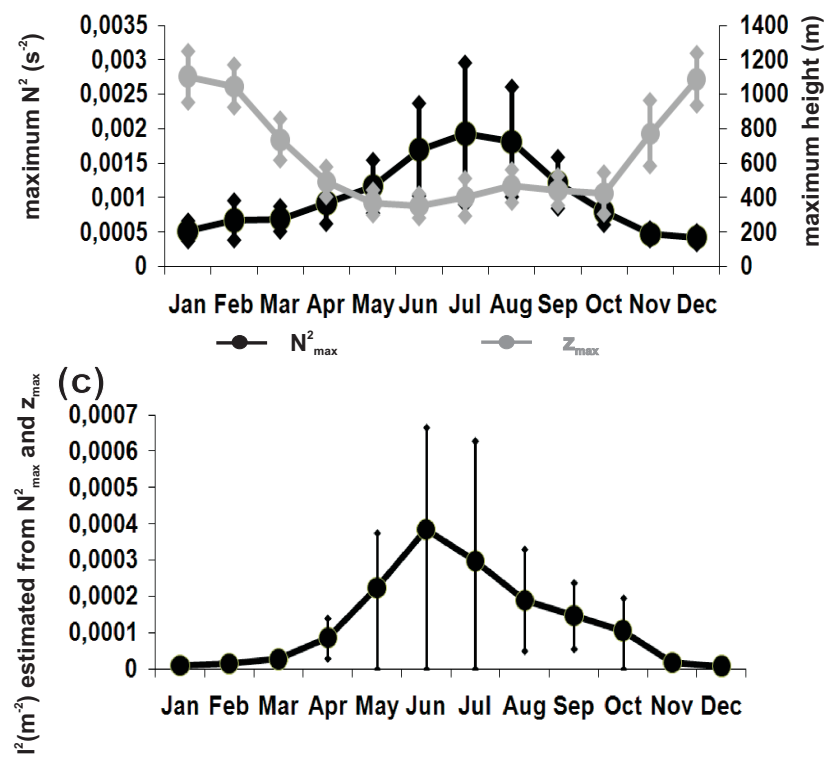

Fig. 4. (a) IW occurrences in Red Sea normalized by number of images per month, for the period between January 1993 and September 2008. (b) Monthly averages of stratification taken from Jeddah weather station, between 1993 and 2008, where $N_{\max }^{2}$ represents the averaged maximum values of $N^{2}$, and $z_{\max }$ represents the heights for which $N^{2}$ was at its maximum. Error bars show standard deviations. (c) Monthly averages of the maximum Scorer parameter estimated for the stratification given in (b) (error bars represent variability due to the standard deviations of $N_{\max }$ and $z_{\max }$ ).

be between $200 \mathrm{~m}$ and $1300 \mathrm{~m}$, see Fig. 2b). In practice, this means that the second term on the right hand side of Eq. (2) is being neglected since $U^{\prime \prime} \approx 0$, because we want to focus on the seasonal trends of the stratification and its dominant role in the pre-conditions for waves propagation. We note that the averaged $U$ used to calculate the averaged $l^{2}$ is only a proxy that changes from case to case. However, a sensitivity analysis reveals that a representative value of $U$ suffices since changing it moderately would not change the conclusions drawn from Fig. 4c. The phase speeds in Eq. (2) have been calculated using a two layer model for long waves $c=\sqrt{g^{\prime} H}$, where the depth of the waveguide $H$ was here set equal to $z_{\max }$. The reduced gravity $g^{\prime}=g\left(\rho_{2}-\rho_{1}\right) / \rho_{1}=0.12 \mathrm{~ms}^{-2}$ was calculated using densities from the case study (upper layer from $1300 \mathrm{~m}$ to $5000 \mathrm{~m}$ with $\rho_{1}=1.087 \mathrm{~kg} \mathrm{~m}^{-3}$; lower 


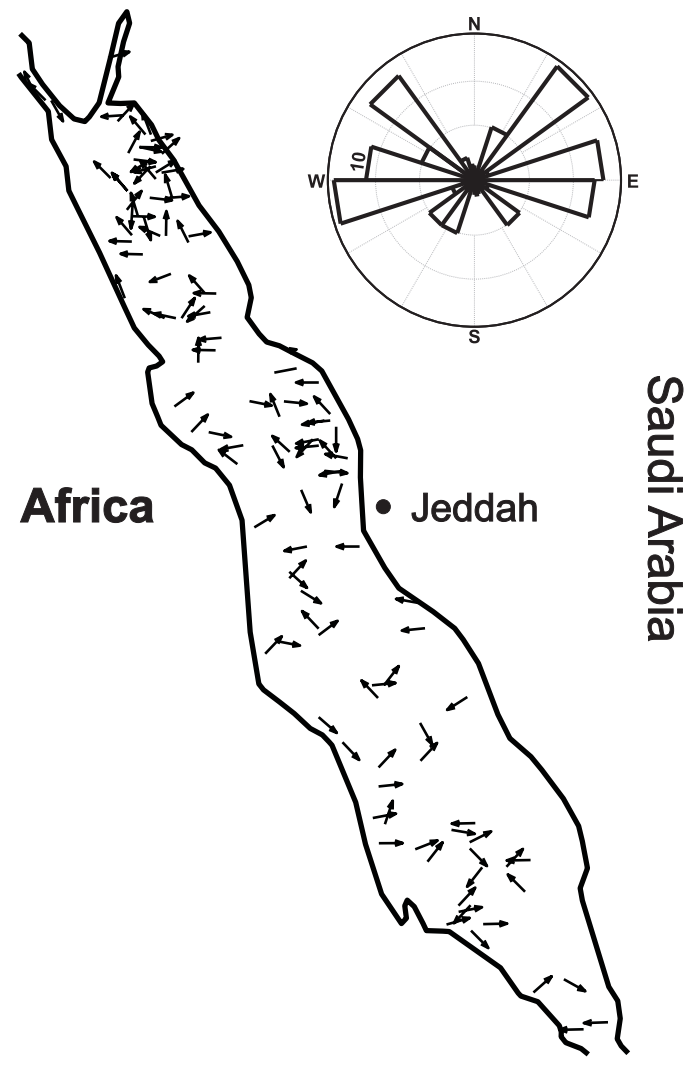

Fig. 5. Map with geographic locations and direction of propagation for all waves in Fig. 4a. At the top right corner an inset shows statistics of propagation directions of the observed AGWs.

layer from $200 \mathrm{~m}$ to $1300 \mathrm{~m}$ with $\rho_{2}=1.100 \mathrm{~kg} \mathrm{~m}^{-3}$ ) as a proxy for the densities in the two-layer model.

Figure $4 \mathrm{c}$ shows that the averaged $l^{2}$ rises substantially between April and September as a consequence of a double contribution from a stronger and shallower stratification (increase in $N_{\max }^{2}$ and decrease in $z_{\max }$ ). Indeed, increases in stratification and decreases in $z_{\max }$ contribute to the increase of the first term in Eq. (2), when considering that $c>U$. Note that according to the expression for the phase speed, $c$ diminishes with $H$ (and therefore with $z_{\max }$ ) decreasing the denominators in Eq. (2), whenever the phase speed approaches the values of $U$. We thus conclude that this seasonal variation in the atmospheric stratification contributes to an increase in the AGW favorable propagation conditions in the period where the wave-like signatures are more often observed (between April and September, see Fig. 4a).

The seasonal stratification of the water column has been analyzed to further investigate the nature of the wave-like signatures accounted in Fig. 4a. In situ temperature data were obtained from a mooring on the shelf edge near the exposed side of Abu Madafi coral reef $\left(22^{\circ} 04.509^{\prime} \mathrm{N}, 38^{\circ} 46.181^{\prime} \mathrm{E}\right.$, see Fig. 1d) between May and October 2008, October 2008 and March 2009, and April 2009 and January 2010. The

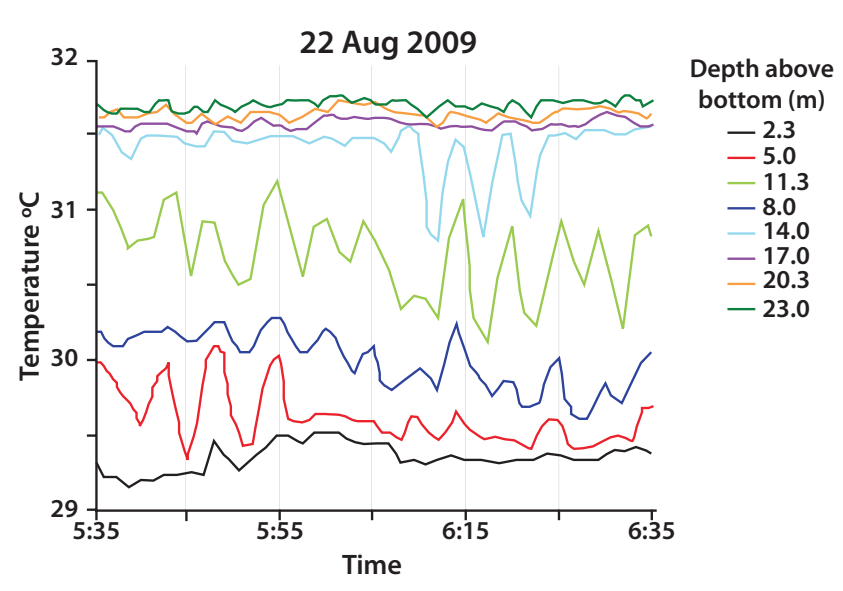

Fig. 6. Temperature measurements for 22 August 2009 near Abu Madafi $\left(22^{\circ} 04.509^{\prime} \mathrm{N}, 38^{\circ} 46.181^{\prime} \mathrm{E}\right)$ using moored temperature loggers at 2.3, 5, 8, 11.3, 14, 17, 20.3 and $23 \mathrm{~m}$ above bottom (bottom depth $\approx 25.2 \mathrm{~m}$ ).

mooring included a sequence of temperature loggers positioned at $2.3,5,8,11.3,14,17,20.3$ and $23 \mathrm{~m}$ above the sea floor (bottom depth $\sim 25.2 \mathrm{~m}$ ). The inclusion of a subsurface buoy insured buoyancy reduced cable movement induced by currents. Overall, the water column was well mixed during the late fall and winter (November to February) and stratified in late spring and summer (May to August). High-frequency temperature oscillations were detected when the water column was stratified and appeared restricted to the lower part of the water column. Figure 6 shows a typical temperature section obtained in the study site (22 August 2009). No evidence of a strong oceanic internal wave field has been found from observations taken from the shelf edge. This result reinforces the idea that not only winter period observations (Fig. 4a) should be of atmospheric waves since there is no stratification in the ocean to sustain internal waves, but also summer large scale observations may be of atmospheric nature. We stress that the high-frequency oscillations in Fig. 6 have periods of the order of $5 \mathrm{~min}$ whilst the satellite observations of internal waves within this area typically have wavelengths (average distance from crest to crest) of $10 \mathrm{~km}$. If these signatures were to be oceanic they would have phase speeds of the order of $30 \mathrm{~m} \mathrm{~s}^{-1}$, which is not a realistic value for oceanic internal waves.

These results, together with the analysis of the atmospheric stability show that the period between April and September is more favorable for AGW propagation, leading to the conclusion that the majority of the signatures observed in satellite imagery of the region are atmospheric.

\section{Dicussions and summary}

This study, combining images from ERS-SAR, EnvisatASAR and MODIS sensors, and oceanic and atmospheric in situ data, shows the existence of suitable propagation 
conditions for AGWs in the Red Sea region, revealing this area as a major hotspot of AGWs in the world. Although AGWs can be found year round, their occurrence is seasonal with a clear increase between April and September. The dominant propagation directions were between ESE and NE and between NW and WSW.

The atmospheric stability $N^{2}$ was used to investigate the existence of waveguides that can trap and prevent energy to radiate away in the vertical. The results show that the stratification plays a key role in determining favorable propagation conditions for AGWs, and that the first term of the Scorer parameter in Eq. (2) can be used as an indicator of these conditions.

The case studies presented in Sect. 2 show that weakly nonlinear long wave models predict phase speeds which are consistent with typical values of observed AGWs, with the $\mathrm{KdV}$ model performing slightly better than the BDAO model as far as estimated phase speeds are concerned. The amplitudes are relatively small compared to the waveguide height (e.g. $a / H \approx 0.04$ for $\mathrm{KdV}$ model in Table 1 ) thus being consistent with the use of weakly nonlinear theory. Note also that, in similar studies, Li et al. (2004) modeled nonlinear AGWs when this ratio was approximately 0.37 and obtained credible results. However, these amplitudes are generally smaller than those presented by Porter and Smyth (2002), who found amplitudes roughly half of the waveguide height. Nevertheless, they also used weakly nonlinear BDAO-type theory, and found reasonable agreement with Morning Glory observations.

The analysis above has also been undertaken for one case study in the Mozambique Channel (the case of a large AGW detected in satellite images dated 16 September 2004, and discussed in detail by da Silva and Magalhaes, 2009). Comparison with the Red Sea AGWs presented in this paper revealed similar characteristics. A similar bottom duct is found over water, and the same conclusions arise from applying $\mathrm{KdV}$ and BDO models, with both being in good agreement with the observed phase speed, and predicting small amplitudes compared to the waveguide height (e.g. $a / H \approx 0.04$ for $\mathrm{KdV})$. Here also, weakly nonlinear theory seems appropriate to describe AGW observations.

Next we discuss briefly some possible generation mechanisms for the observed AGWs. The conjectures that follow are plausible explanations for wave generation based on our knowledge of the meteorology of the study region, whereas a more developed study is beyond the scope of the present paper. Mountain chains surrounding the Red Sea help constrain the average flow along its main axis (Patzert, 1974). Nevertheless, mesoscale atmospheric modeling (validated by in situ data) was used by Jiang et al. (2009) to add important results focusing on the cross-axis zonal winds within the Red Sea region. In fact, they found that the complex topography of the Red Sea contains several gaps along the coast, and that these direct numerous strong jet-like winds up to $15 \mathrm{~m} \mathrm{~s}^{-1}$ (with a significant zonal component) to flow fre- quently across the longitudinal axis of the Red Sea. This general frame of circulation is in agreement with the AGWs preferential directions of propagation presented in Fig. 5, where it is clearly seen that AGWs also have a strong zonal component. This encourages us to believe that several AGW wind driven generation mechanisms may be at work in the Red Sea, and that these are most likely related to the strong jetlike winds and variable topography. These wave generation mechanisms are commonly known as lee wave generation and upstream generation (see e.g. Vachon et al., 1994; Li et al., 2004). Particularly interesting is also the fact that some AGWs have phase lines (crests) almost parallel to the coastlines (see also the propagation directions in the map provided in Fig. 5). Since there are usually strong (daily) temperature contrasts along the Red Sea coasts (Pedgley, 1974) that could result in sea/land breezes, these could generate AGWs when they are sufficiently strong.

As these large-amplitude waves occur frequently near some airports, such as Jeddah International Airport in Saudi Arabia, knowledge of the pre-conditions for their propagation and near real time satellite observations can become useful for aircraft operation at low altitudes in the Red Sea and its coastal zone.

Finally, we believe that the distinction issue between oceanic and atmospheric internal waves in satellite images should not be neglected particularly in regions such as the Red Sea region (characterized by dry conditions and absence of roll clouds). Whilst many of the IWs in satellite observations in the Red Sea region can be interpreted as AGWs based solely on scale, refraction patterns and surface signatures (such as the case study in Fig. 1), there are oceanic IWs in the Red Sea (as shown by Jackson, 2007) that cannot be interpreted based on these criteria alone (especially when wavelengths approach values around 5-10 km).

Acknowledgements. This research was conducted with support from KAUST (King Abdullah University for Science and Technology) in collaboration with the Woods Hole Oceanographic Institution, Biology Department. The views expressed in this manuscript are those of the authors and do not necessarily represent the official opinion of KAUST. Some support was also provided by a Treaty of Windsor Grant awarded by the British Council (Portugal). SAR image data was provided by ESA under contract AOPT-2423. One of us would like to thank the Portuguese Science and Technology Foundation (FCT) for a research grant (SFRH/BD/35898/2007).

Edited by: K. Helfrich

Reviewed by: two anonymous referees 


\section{References}

Alpers, W.: Theory of radar imaging of internal waves, Nature, 314, 245-247, 1985.

Alpers, W. and Stilke, G.: Observations of a nonlinear wave disturbance in marine atmosphere by synthetic aperture radar aboard the ERS 1 satellite, J. Geophys. Res., 101, 6512-6525, 1996.

Bedard, A. J., Canavero, F., and Einaudi, F.: Atmospheric gravity waves and aircraft turbulence encounters, J. Atmos. Sci., 43(23), 2838-2844, 1986.

Christie, D. R.: Long nonlinear waves in the lower atmosphere, J. Atmos. Sci., 46(11), 1462-1491, 1989.

Christie, D. R. and Muirhead, K. J.: Solitary waves: a hazard to aircraft operating at low altitudes, Aust. Met. Mag., 31, 97-109, 1983.

Crook, A. N.: The effect of ambient stratification and moisture on the motion of atmospheric undular bores, J. Atmos. Sci., 43(2), 171-181, 1986.

Crook, A. N.: Trapping of low-level internal gravity waves, J. Atmos. Sci., 45(10), 1533-1541, doi:10.1175/15200469(1988)045, 1988.

Da Silva, J. C. B. and Magalhaes, J. M.: Satellites observations of large atmospheric gravity waves in the Mozambique Channel, Int. J. Rem. Sens., 30(5), 1161-1182, 2009.

Da Silva, J. C. B., Ermakov, S. A., and Robinson, I. S.: Role of surface films in ERS SAR signatures of internal waves on the shelf. III. Mode transitions, J. Geophys. Res., 105(C10), 2408924104, doi:10.1029/2000JC900053, 2000.

Da Silva, J. C. B., New, A. L., and Azevedo, A.: On the role of SAR for observing "local generation" of internal solitary waves off the Iberian Peninsula, Canad. J. Rem. Sens., 33(5), 388-403, 2007.

Da Silva, J. C. B., New, A. L., and Magalhaes, J. M.: Internal Solitary waves in the Mozambique Channel: Observations and interpretation, J. Geophys. Res.-Oceans, 114, C05001, doi:10.1029/2008JC005125, 2009.

Gan, X. L., Huang, W. G., Li, X. F., Chen, X. J., Lou, X. L., Zhao, Z. X., Yang, J. S., and Shi, A. Q.: Coastally trapped atmospheric waves on SAR, AVHRR and MODIS images, Inter. J. Rem. Sens., 29(6), 1621-1634, doi:10.1080/01431160701395260, 2008.

Grimshaw. R. H. J. (Ed.): Environmental Stratified Flows, Topics in Environmental Fluid Mechanics, 282 pp., Kluwer Academic Publishers, Boston, 2002.

Jackson, C. R. (Ed.): An Atlas of internal solitary-like waves and their properties, 2nd ed., 559 pp., http://www.internalwaveatlas. com, Global Ocean Associates, Alexandria, VA, 2004.

Jackson, C.: Internal wave detection using the moderate resolution imaging spectroradiometer (MODIS), J. Geophys. Res., 112, C11012, doi:10.1029/2007JC004220, 2007.

Jackson, C. R. and Apel, J. R. (Eds.): An Atlas of internal solitarylike waves and their properties, 1st ed., 559 pp., http://www. internalwaveatlas.com, Global Ocean Associates, Alexandria, VA, 2002.
Jiang, H., Farrar, J. T., Beardsley, R. C., Chen, R., and Chen, C.: Zonal surface wind jets across the Red Sea due to mountain gap forcing along both sides of the Red Sea, Geophys. Res. Lett., 36, L19605, doi:10.1029/2009GL040008, 2009.

Kim, D. J., Nam, S., Kim, H. R., Moon, W. M., and Kim, K.: Can near-inertial internal waves in the East Sea be observed by synthetic aperture radar?, Geophys. Res. Lett., 32, L02606, doi:10.1029/2004GL021532, 2005a.

Kim, H. R., Nam, S. H., Kim, D. J., Kim, K., and Moon, W. M.: Reply to comment by Q. Zheng on 'Can near-inertial internal waves in the East Sea be observed by synthetic aperture radar?', Geophys.Res. Lett., 32(20), L20607, doi:10.1029/2005GL024351, 2005b.

Li, X. F., Dong, C., C-Colón, P., Pichel, W. G., and Friedman, K. S.: Synthetic aperture radar observation of the sea surface imprints of upstream atmospheric solitons generated by flow impeded by an island, J. Geophys. Res., 109, C02016, doi:10.1029/2003JC002168, 2004.

Noonan, J. A. and Smith, R. K.: Linear and weakly nonlinear internal wave theories applied to 'morning glory' waves, Geophys. Astro. Fluid Dyn., 33, 123-143, 1985.

Patzert, W. C.: Wind-induced reversal in Red Sea circulation, Deep Sea Res., 21, 109-121, 1974.

Pedgley, D. E.: An outline of the weather and climate of the Red Sea, in: L'Oceanographie Physique de la Mer Rouge, pp. 9-27, U. N. Ed. Sci. and Cult. Org., Paris, 1974.

Porter, A. and Smyth, N. F.: Modelling the morning glory of the Gulf of Carpentaria, J. Fluid Mech., 454, 1-20, doi:10.1017/S0022112001007455, 2002.

Rottman, J. W. and Einaudi, F.: Solitary waves in the atmosphere, J. Atmos. Sci., 50, 2116-2136, 1992.

Rottman, J. W. and Grimshaw, R.: Atmospheric internal solitary waves, Environmental Stratified Flows, edited by: Grimshaw, R., 61-88, Kluwer Academic Publishers, Boston, 2002.

Scorer, R. S.: Theory of waves in the lee of mountains, Q. J. Roy. Meteorol. Soc., 75(323), 41-56, doi:10.1002/qj.49707532308, 1949.

Smith, R. K.: Travelling waves and bores in the lower atmosphere: the 'Morning Glory' and related phenomena, Earth-Sci. Rev., 25, 267-290, 1988.

Vachon, P. W., Johannessen, O. M., and Johannessen, J. A.: An ERS-1 synthetic aperture radar image of atmospheric lee waves, J. Geophys. Res., 99(22), 483-490, 1994.

Vlasenko, V., Stashchuk, N., and Hutter, K. (Eds.): Baroclinic Tides: Theoretical Modeling and Observational Evidence, 351 pp., Cambridge University Press, New York, 2005.

Zheng, Q.: Comment on "Can near-inertial internal waves in the East Sea be observed by synthetic aperture radar?" by D. J. Kim et al., Geophys. Res. Lett., 32, L20606, doi:10.1029/2005GL023770, 2005. 